\title{
Pilot Scale Biological Treatment as Pre-Treatment for Reverse Osmosis
}

\author{
Sareddy Ravi Sankara Reddy, Manoj Kumar Karnena, Vara Saritha* \\ Department of Environmental Studies, GITAM Institute of Science, GITAM (Deemed to be University), Visakhapatnam, India \\ Email: *vsjr08@gmail.com
}

How to cite this paper: Reddy, S.R.S., Karnena, M.K. and Saritha, V. (2019) Pilot Scale Biological Treatment as Pre-Treatment for Reverse Osmosis. Journal of Water Resource and Protection, 11, 1369-1388. https://doi.org/10.4236/jwarp.2019.1111079

Received: October 14, 2019

Accepted: November 11, 2019

Published: November 14, 2019

Copyright $\odot 2019$ by author(s) and Scientific Research Publishing Inc. This work is licensed under the Creative Commons Attribution International License (CC BY 4.0).

http://creativecommons.org/licenses/by/4.0/ CC) (i) Open Access

\begin{abstract}
Treatment of pharmaceutical wastewaters is a challenging task owing to their complexity and pollution load, variability in strength of waste streams accompanied with shock loads. Since no single treatment system is a viable option, integration of existing systems with advanced physical/chemical processes has been gaining attention for treatment of pharmaceutical wastewater. In the present study, two biological treatment methods were evaluated for their efficiency as pre-treatment system for RO which are sequencing batch reactor and membrane bioreactor. Efficiency of biological treatments tested SBR and MBR was presented in terms of percentage removal of physico-chemical parameters. Total dissolved solids removal by SBR was $31.82 \%$ while MBR showed $29.25 \%$ reduction. Chemical oxygen demand removal by SBR was 69.54\% while MBR showed 30.35\% removal. Efficiency of combined treatments SBR-RO and MBR-RO was presented in terms of removal of total dissolved solids, COD and ammonia. TDS removal was the highest in the combination of SBR-RO with $95.94 \%$ removal, while MBR-RO combination resulted in $87.29 \%$ removal. Chemical oxygen demand was achieved maximum with the combination of MBR-RO $92.33 \%$ while competitive results were achieved with the combination SBR-RO also with $88.62 \%$ removal. Removal of ammonia was maximum with the combination SBR-RO $87.5 \%$, while competitive results were obtained with MBR-RO 85.51\%. From the results, it can be understood that SBR was efficient in removing ammonia, total dissolved solids and was equally competent in removing chemical oxygen demand. This study concludes that combined treatment of SBR-RO proves to be promising in treating pharmaceutical wastewaters.
\end{abstract}

\section{Keywords}

Reverse Osmosis, Membrane Reactor, Sequencing Batch Reactor, Waste Water 


\section{Introduction}

Treatment of pharmaceutical wastewaters is a challenging task owing to their complexity and pollution load, variability in strength of waste streams with shock loads. These factors govern the effectiveness of conventional treatment systems. Since no single treatment system is a viable option, integration of existing systems with advanced physical/chemical processes has been gaining attention for treatment of pharmaceutical wastewater.

Simplicity in process and single tank design of SBR coupled with flexible technology has been recognized as a desirable treatment option for different types of wastewater [1]-[6]. Unique characteristics of SBR include its competence in removal both organic matter and nitrogen from wastewater [7] [8] [9]. Conditions of both aerobic and anaerobic can be adopted in SBR for removal of phosphorus [10] [11] [12]. These properties of SBR make it viable economically [13].

SBR applied for treatment of olive mill wastewaters showed significant removal of pollution load through $60 \%$ removal of total polyphenols and $90 \%$ removal of chemical oxygen demand respectively [14]. When used to treat swine wastewater the reactor presented excellent purification of wastewaters. Removal of total phosphorus, total nitrogen ammonia-nitrogen and COD were in the order of $96.2 \%, 95.6 \%, 95.7 \%$, and $98.2 \%$ respectively [15]. SBR treatment was also adopted for pharmaceutical wastewaters, though less work has been reported the results were promising. Study of wastewater containing antibiotic was carried out by Elmolla and Chaudhuri, 2011 [16].

Modern hybrid wastewater treatment adopting membrane separation technology along with biological process is Membrane bio-reactor (MBR) [17]. Utilized as biochemical engineering processes, MBR can be used as suspended growth bioreactor functioning processes like bio-oxidation, fermentation, nitrification and denitrification along with separation of solid and liquid [18]. Further, this can also be operated at high sludge concentrations [19]. MBRs are well appreciated for their efficiency in removing dissolved solids [20] [21]. Major concern of MBR system is fouling of membrane which indicates accumulation of rejected constituents on the membrane resulting in resistance to water transport through the membrane [22]. Greater than $80 \%$ removal efficiency for pharmaceuticals was reported by Radjenovic et al., 2007 [23].

Membrane technologies have gained significant importance in treating wide array of industrial wastewaters during the past decades. Among others, reverse osmosis (RO) has been specifically appreciated as state of art in treatment of wastewater. $\mathrm{RO}$ has been adopted for treating industrial wastewaters from petrochemical, chemical, pulp and paper, food industries, electrochemical, municipal wastewater, textile and also for treatment of drinking water [24] [25] [26]. Permeate from this process has high quality with potential to reuse for various processes like dyeing, boilers cooling-towers and cleaning, etc.

However, application of $\mathrm{RO}$ faces major hurdle with reference to membrane fouling which impacts efficiency of treatment both qualitatively and quantita- 
tively, increasing operation costs due to resistance in filtration, production of corrosive by-products and passage of salts [27] [28]. Owing to fouling reason extensive pre-treatment is required for successful functioning of these systems [29] [30]. Comparative study between conventional biological treatment and MBR as pre-treatment options for RO was studied and revealed that MBR was more suitable [31]. Current research focusses on testing the efficiency of biological treatments SBR and MBR as viable pre-treatment options for RO.

\section{Methodology}

\subsection{Process}

Biological treatment using sequencing batch reactor and membrane bioreactor was studied. Efficiency of the process was evaluated in terms of reduction in total dissolved solids and chemical oxygen demand. Treated waters from each of the unit are fed to reverse osmosis for a duration of one month to evaluate their efficiency as pre-treatment to reverse osmosis (Figure 1).

\subsection{Sampling Site and Sample Collection}

All the samples were collected from the treatment plant of the pharmaceutical industry. Water samples from sequencing batch reactor and membrane bioreactor were collected once every day. Samples from sequencing batch reactor were collected from feed and outlet respectively and for membrane bioreactor and reverse osmosis samples from feed, permeate and reject were collected.

\subsection{Analytical Procedures}

The following parameters for the collected samples were analysed $\mathrm{pH}$, total dissolved solids and chemical oxygen demand. All parameters were analysed as per the standard methods of APHA, 2015 (Table 1).

\section{Results}

This research presents the results from pilot scale studies focussed on to study the most suitable pre-treatment for reverse osmosis (RO) treatment. Sequencing batch reactor (SBR) and Membrane bioreactor (MBR) were assessed for their suitability as pre-treatment options to RO.

Table 2 illustrates one month (June, 2016) data of SBR tested for its suitability

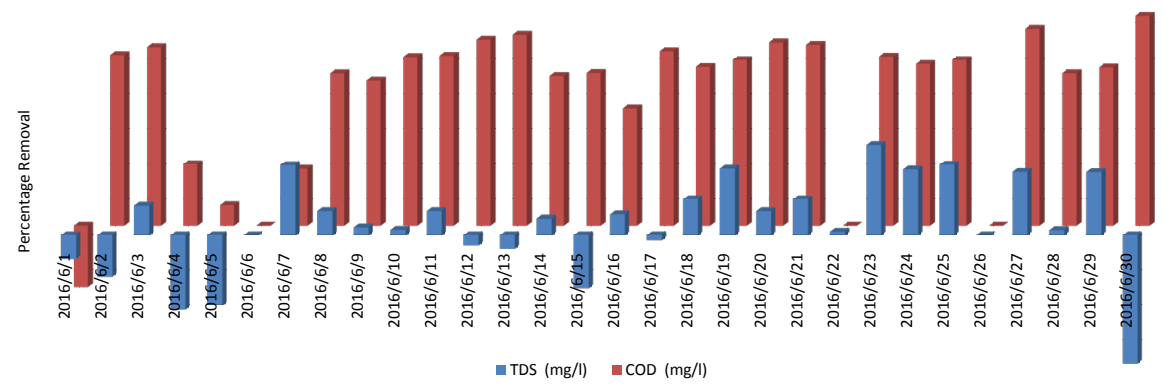

Figure 1. Percentage removal of TDS and COD in SBR pilot trails during June, 2016. 
Table 1. APHA methods (2005).

\begin{tabular}{ccc}
\hline S.No & Parameter & Method of Analysis \\
\hline 1. & $\mathrm{pH}$ & APHA Standard Method 4500 \\
2. & Total Dissolved Solids & APHA Standard Method 2540C \\
3. & Chemical Oxygen Demand & APHA Standard Method 5220 \\
\hline
\end{tabular}

Table 2. Removal of TDS and COD in the SBR pilot trail.

\begin{tabular}{cccccc}
\hline Date & TDS (mg/l) & COD (mg/l) & Date & TDS (mg/l) & COD (mg/l) \\
\hline $01-06-2016$ & -8.41 & -21.88 & $16-06-2016$ & 7.20 & 41.51 \\
$02-06-2016$ & -14.95 & 60.61 & $17-06-2016$ & -1.90 & 61.95 \\
$03-06-2016$ & 10.16 & 63.33 & $18-06-2016$ & 12.50 & 56.32 \\
$04-06-2016$ & -26.67 & 21.64 & $19-06-2016$ & 23.36 & 58.84 \\
$05-06-2016$ & -25.00 & 6.98 & $20-06-2016$ & 8.33 & 64.96 \\
$06-06-2016$ & 0.00 & 0.00 & $21-06-2016$ & 12.50 & 64.08 \\
$07-06-2016$ & 24.66 & 20.00 & $22-06-2016$ & 1.27 & 0.00 \\
$08-06-2016$ & 8.33 & 54.06 & $23-06-2016$ & 31.82 & 60.08 \\
$09-06-2016$ & 2.78 & 51.53 & $24-06-2016$ & 23.08 & 57.37 \\
$10-06-2016$ & 1.90 & 59.97 & $25-06-2016$ & 24.82 & 58.84 \\
$11-06-2016$ & 8.33 & 60.37 & $26-06-2016$ & 0.00 & 0.00 \\
$12-06-2016$ & -3.70 & 65.86 & $27-06-2016$ & 22.22 & 69.54 \\
$13-06-2016$ & -4.89 & 67.55 & $28-06-2016$ & 1.82 & 54.08 \\
$14-06-2016$ & 5.77 & 53.13 & $29-06-2016$ & 22.14 & 56.12 \\
$15-06-2016$ & -18.93 & 54.19 & $30-06-2016$ & -45.58 & 74.35 \\
\hline
\end{tabular}

as preliminary treatment for Reverse Osmosis process. One month data on a daily basis was presented. Efficiency of the process was tested with reduction in parameters total dissolved solids and chemical oxygen demand. Further as surrogate for removal of TDS and COD, sludge volume and dissolved oxygen respectively were also recorded. The highest and lowest TDS reduction was recorded as $31.82 \%$ and $-45.58 \%$ on 23 rd and 30 th June respectively. Reduction in COD was observed to be good in comparison with reduction of TDS the highest and the lowest reduction percentages were recorded as $24.82 \%$ and $-45.58 \%$ on 25th and 30th June respectively. In line with the poor removal of TDS sludge volume has recorded the lowest values ranging from $40-280 \mathrm{ml}$. Dissolved oxygen values ranged between 4.4 to $6.1 \mathrm{mg} / \mathrm{l}$ (Figure 1).

Table 3 presents one month trail run of Reverse Osmosis treatment, which was fed with SBR outlet. Percentage removal of TDS from RO treatment was noted at the highest and lowest as $96 \%$ and $78.18 \%$ respectively. Maximum and minimum percentage of COD removal was $88.62 \%$ and $64.62 \%$ respectively.

Percentage reduction of ammonia with maximum and minimum was $87.50 \%$ and $78.00 \%$ respectively (Figure 2 ). 
Table 3. Efficiency of RO with SBR as pre-treatment with reference to reduction in TDS and COD.

\begin{tabular}{|c|c|c|c|c|c|c|c|}
\hline Date & TDS & COD & Ammonia & Date & TDS & COD & Ammonia \\
\hline 01-06-2016 & 92.82 & 64.62 & 82.17 & $17-06-2016$ & 87.90 & 85.70 & 78.84 \\
\hline $02-06-2016$ & 90.26 & 74.87 & 80.23 & $18-06-2016$ & 87.85 & 87.72 & 84.34 \\
\hline 03-06-2016 & 78.18 & 78.18 & 82.61 & $19-06-2016$ & 87.14 & 86.22 & 80.90 \\
\hline 04-06-2016 & 95.29 & 81.33 & 82.55 & $20-06-2016$ & 85.24 & 87.23 & 0.00 \\
\hline $05-06-2016$ & 95.94 & 82.25 & 0.00 & $21-06-2016$ & 87.27 & 84.52 & 80.20 \\
\hline 07-06-2016 & 94.39 & 0.00 & 87.50 & $22-06-2016$ & 84.76 & 83.06 & 82.53 \\
\hline 08-06-2016 & 94.29 & 74.76 & 84.86 & $23-06-2016$ & 86.41 & 83.40 & 78.25 \\
\hline 09-06-2016 & 92.33 & 74.33 & 84.26 & $24-06-2016$ & 81.03 & 86.67 & 81.88 \\
\hline $10-06-2016$ & 96.00 & 75.07 & 83.39 & $25-06-2016$ & 88.00 & 83.21 & 80.09 \\
\hline $11-06-2016$ & 94.69 & 76.49 & 84.62 & $26-06-2016$ & 84.95 & 0.00 & 78.00 \\
\hline $12-06-2016$ & 94.52 & 88.62 & 0.00 & $27-06-2016$ & 0 & 85.11 & 79.19 \\
\hline $13-06-2016$ & 93.98 & 84.88 & 80.99 & $28-06-2016$ & 80.48 & 84.22 & 81.90 \\
\hline $14-06-2016$ & 94.08 & 85.51 & 82.05 & $29-06-2016$ & 82.22 & 83.81 & - \\
\hline $15-06-2016$ & 92.94 & 82.75 & 81.57 & $30-06-2016$ & - & 82.06 & - \\
\hline $16-06-2016$ & - & 88.19 & 79.91 & - & - & - & - \\
\hline
\end{tabular}

Efficiency of Reverse Osmosis with SBR as pre-treatment

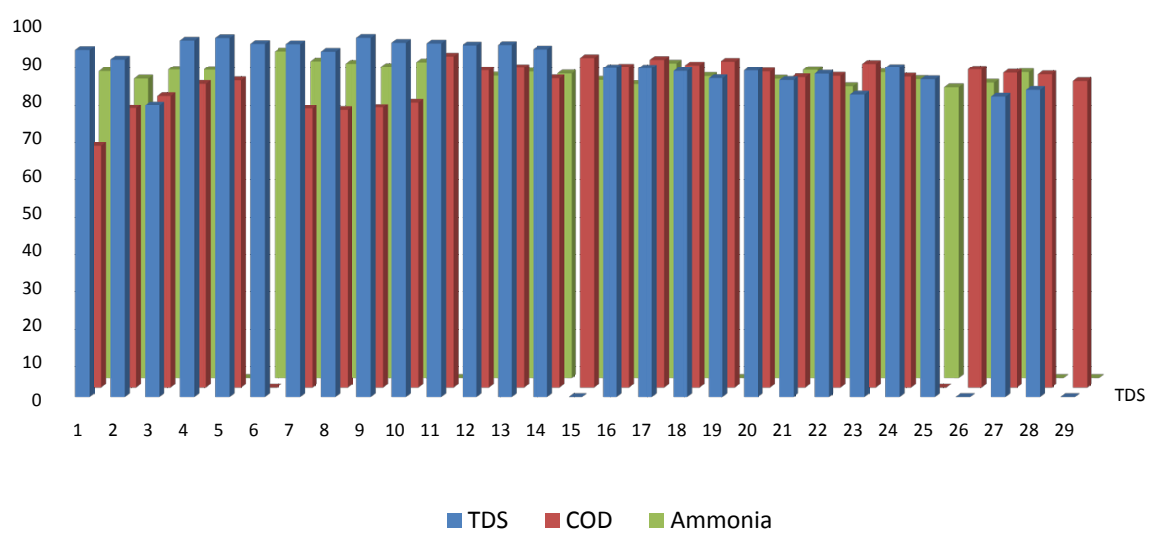

Figure 2. Percentage removal of TDS, COD and ammonia in RO with SBR as pre-treatment pilot trails during June, 2016.

Table 4 presents the biological treatment of pharmaceutical wastewaters using membrane bioreactor (MBR) on pilot trail during the month of August 2016. Efficiency of the treatment is defined in terms of reduction in strength of wastewaters with parameters of total dissolved solids, total solids, chemical oxygen demand and turbidity. The percentage removal of the parameters under test, as understood from the permeate values the TDS removal was recorded to be $1.38 \%$ as the lowest and $29.25 \%$ as the highest. While TSS has showed $100 \%$ removal, the COD removal varied from $4.77 \%$ to $30.35 \%$. Turbidity removal was good with $80.90 \%$ being the lowest and $99.86 \%$ recorded as the highest (Figure 3 ). 
Table 4. Efficiency of MBR treatment presented in terms of percentage removal.

\begin{tabular}{cccccccccc}
\hline Day & TDS & TSS & COD & Turbidity & Day & TDS & TSS & COD & Turbidity \\
\hline 1 & 1.38 & 100 & 4.77 & 99.66 & 16 & 13.78 & 100 & 6.28 & 99.72 \\
2 & 3.36 & 100 & 11.15 & 99.50 & 17 & 20.27 & 100 & 5.08 & 99.73 \\
3 & 2.47 & 100 & 26.64 & 99.05 & 18 & 12.41 & 100 & 8.16 & 99.44 \\
4 & 29.25 & 100 & 16.00 & 99.77 & 19 & 14.81 & 100 & 17.28 & 99.59 \\
5 & 6.23 & 100 & 19.06 & 99.79 & 20 & 11.62 & 100 & 12.65 & 99.79 \\
6 & 7.82 & 100 & 11.17 & 99.81 & 21 & 10.66 & 100 & 26.41 & 99.33 \\
7 & 6.09 & 100 & 30.35 & 80.90 & 22 & 5.74 & 100 & 22.36 & 99.74 \\
8 & 16.79 & 100 & 11.76 & 98.95 & 23 & 5.98 & 100 & 20.09 & 99.71 \\
9 & 1.38 & 100 & 4.77 & 99.66 & 24 & 9.22 & 100 & 10.70 & 99.79 \\
10 & 10.82 & 100 & 11.36 & 99.82 & 25 & 12.02 & 100 & 26.28 & 99.49 \\
11 & 11.38 & 100 & 5.94 & 99.68 & 26 & 7.30 & 100 & 14.42 & 99.65 \\
12 & 13.65 & 100 & 9.07 & 99.63 & 27 & 10.07 & 100 & 16.08 & 99.51 \\
13 & 13.95 & 100 & 10.10 & 99.72 & 28 & 6.16 & 100 & 8.34 & 99.83 \\
14 & 9.59 & 100 & 15.42 & 99.73 & 29 & 13.30 & 100 & 13.65 & 99.86 \\
15 & 14.17 & 100 & 13.95 & 99.55 & 30 & 8.52 & 100 & 9.78 & 99.57 \\
\hline & & & & & & & & & \\
\hline
\end{tabular}

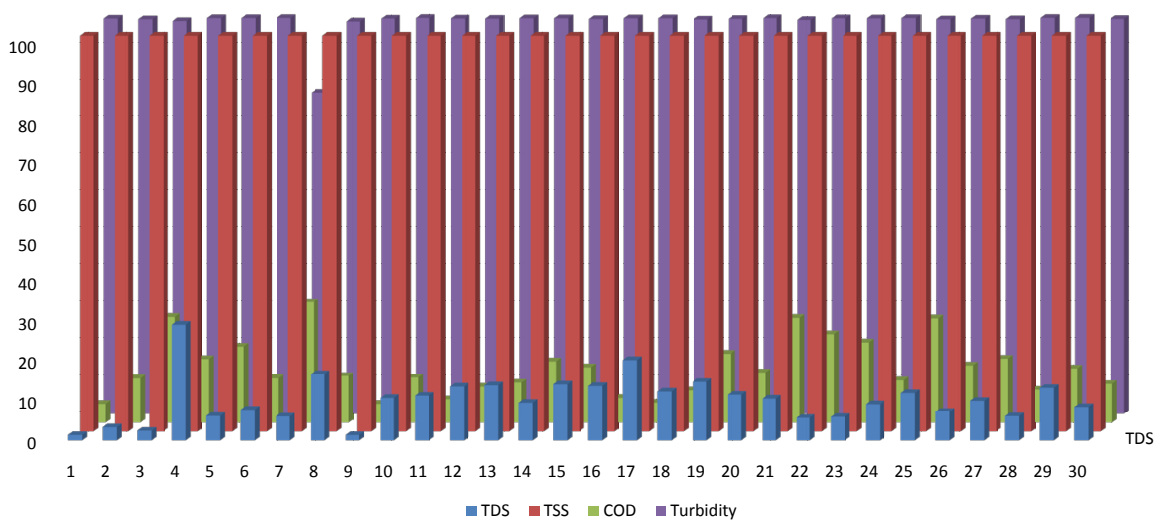

Figure 3. Efficiency of MBR treatment.

Table 5 presents treatment with reverse osmosis with membrane bioreactor as pre-treatment. Feed waters contained high concentrations of all parameters under test. The percentage removal of the parameters under test as understood from the permeate values the TDS removal was recorded to be $76.96 \%$ as the lowest and $87.29 \%$ as the highest. COD removal varied from $73.03 \%$ to $92.33 \%$. While hardness showed $93.33 \%$ - 100\% removal, ammonia removal was good with $71.46 \%$ being the lowest and $85.51 \%$ recorded as the highest (Figure 4 ).

Table 6 illustrates the comparison of total dissolved solids and chemical oxygen demand removal by sequencing batch reactor and membrane bioreactor. Maximum reduction of total dissolved solids was obtained by SBR with $31.82 \%$ while minimum was also obtained by SBR with $-74.58 \%$. On the other hand, 
Table 5. Efficiency of RO with MBR as pre-treatment with reference to TDS and COD Reduction.

\begin{tabular}{cccccccccc}
\hline Day & TDS & COD & $\mathrm{NH}_{3}$ & Hardness & Day & TDS & COD & $\mathrm{NH}_{3}$ & Hardness \\
\hline 1 & 76.96 & 83.23 & 79.63 & 100.00 & 14 & 79.57 & 76.90 & 83.93 & 98.26 \\
2 & 85.88 & 83.64 & 77.81 & 100.00 & 15 & 80.00 & 81.29 & 82.85 & 97.50 \\
3 & 87.29 & 82.22 & 78.46 & 100.00 & 16 & 81.70 & 76.09 & 80.28 & 94.29 \\
4 & 85.19 & 84.91 & 80.71 & 100.00 & 17 & 83.75 & 82.18 & 0.00 & 95.86 \\
5 & 84.23 & 85.11 & 81.51 & 00.00 & 18 & 83.93 & 85.28 & 0.00 & 0.00 \\
6 & 80.95 & 88.17 & 81.88 & 100.00 & 19 & 78.79 & 86.77 & 71.46 & 97.56 \\
7 & 84.60 & 86.31 & 84.29 & 100.00 & 20 & 78.95 & 88.55 & 81.25 & 96.67 \\
8 & 80.84 & 86.91 & 84.48 & 100.00 & 21 & 79.29 & 89.47 & 74.29 & 96.36 \\
9 & 82.85 & 84.97 & 83.75 & 95.19 & 22 & 86.92 & 90.12 & 76.25 & 97.32 \\
10 & 84.03 & 86.91 & 80.27 & 96.19 & 23 & 83.48 & 89.19 & 77.69 & 98.23 \\
11 & 77.80 & 73.03 & 82.35 & 98.26 & 24 & 86.50 & 90.26 & 79.00 & 96.92 \\
12 & 85.00 & 79.29 & 84.29 & 97.27 & 25 & 84.94 & 91.69 & 81.97 & 95.45 \\
\hline 13 & 82.55 & 77.65 & 85.51 & 97.14 & 26 & 86.67 & 92.33 & 80.15 & 93.33 \\
\hline
\end{tabular}

Table 6. Comparison of TDS and COD removal after treatment with SBR and MBR.

\begin{tabular}{|c|c|c|c|c|c|c|c|c|c|}
\hline \multirow{2}{*}{ Day } & \multicolumn{2}{|c|}{ TDS } & \multicolumn{2}{|c|}{ COD } & \multirow{2}{*}{ Day } & \multicolumn{2}{|c|}{ TDS } & \multicolumn{2}{|c|}{ COD } \\
\hline & SBR & MBR & SBR & MBR & & SBR & MBR & SBR & MBR \\
\hline 1 & -8.41 & 1.38 & -21.88 & 4.77 & & 7.2 & 13.78 & 41.51 & 6.28 \\
\hline 2 & -14.95 & 3.36 & 60.61 & 11.15 & 17 & -1.9 & 20.27 & 61.95 & 5.08 \\
\hline 3 & 10.16 & 2.47 & 63.33 & 26.64 & 18 & 12.5 & 12.41 & 56.32 & 8.16 \\
\hline 4 & -26.67 & 29.25 & 21.64 & 16 & 19 & 23.36 & 14.81 & 58.84 & 17.28 \\
\hline 5 & -25 & 6.23 & 6.98 & 19.06 & 20 & 8.33 & 11.62 & 64.96 & 12.65 \\
\hline 6 & 0 & 7.82 & 0 & 11.17 & 21 & 12.5 & 10.66 & 64.08 & 26.41 \\
\hline 7 & 24.66 & 6.09 & 20 & 30.35 & 22 & -74.58 & 5.74 & 0 & 22.36 \\
\hline 8 & 8.33 & 16.79 & 54.06 & 11.76 & 23 & 31.82 & 5.98 & 60.08 & 20.09 \\
\hline 9 & 2.78 & 1.38 & 51.53 & 4.77 & 24 & 23.08 & 9.22 & 57.37 & 10.7 \\
\hline 10 & 1.9 & 10.82 & 59.97 & 11.36 & 25 & 24.82 & 12.02 & 58.84 & 26.28 \\
\hline 11 & 8.33 & 11.38 & 60.37 & 5.94 & 26 & 0 & 7.3 & 0 & 14.42 \\
\hline 12 & -3.7 & 13.65 & 65.86 & 9.07 & 27 & 22.22 & 10.07 & 69.54 & 16.08 \\
\hline 13 & -4.89 & 13.95 & 67.55 & 10.1 & 28 & 1.82 & 6.16 & 54.08 & 8.34 \\
\hline 14 & 5.77 & 9.59 & 53.13 & 15.42 & 29 & 22.14 & 13.3 & 56.12 & 13.65 \\
\hline 15 & -18.93 & 14.17 & 54.19 & 13.95 & 30 & -45.58 & 8.52 & 74.35 & 9.78 \\
\hline
\end{tabular}

MBR present lowest removals with $1.38 \%$ and $29.25 \%$ as the lowest and the highest. The average removal for TDS was the highest with MBR (10.33\%) since it was stable without going to negative values. SBR, even though presented the 
highest removal was quite fluctuating in treatment process. Chemical oxygen demand was also the highest (69.54\%) with SBR and the lowest also by SBR with $-21.88 \%$, while MBR was stable with minimum of $4.77 \%$ and maximum of $30.35 \%$ removal of COD. The average removal of COD was the highest with SBR with $42.51 \%$ and MBR being only $13.96 \%$ (Figure 5 and Figure 6).

Comparison of treatment efficiency of reverse osmosis with SBR and MBR as pre-treatment in terms of TDS, COD and Ammonia removal is presented in Table 7. Total dissolved solids removal was the highest in the combination of SBR-RO

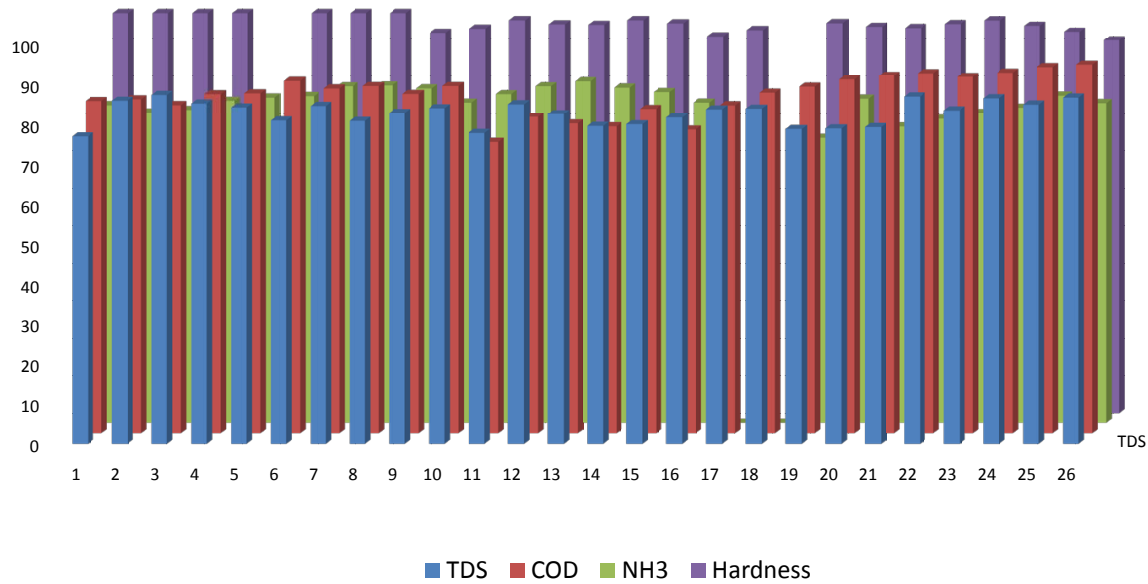

Figure 4. Efficiency of RO with MBR as pre-treatment.

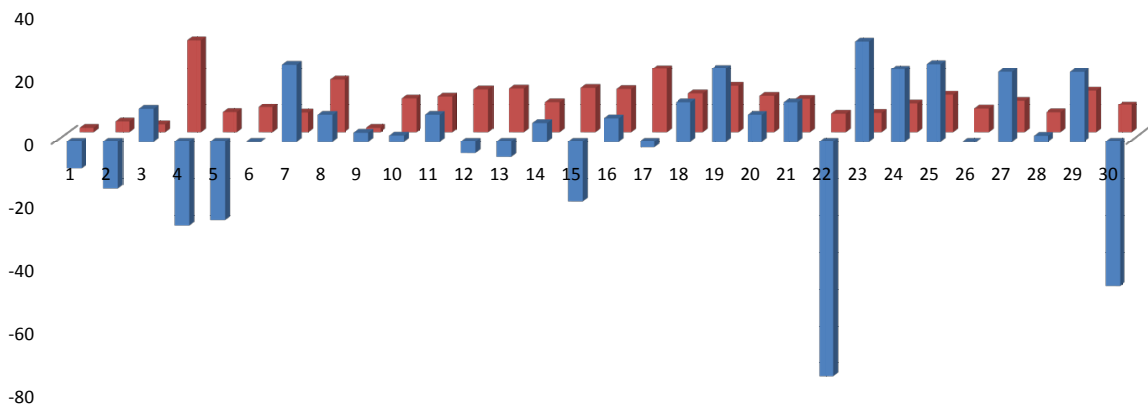

$\square \mathrm{SBR} \square \mathrm{MBR}$

Figure 5. Comparison of TDS removal with SBR and MBR.

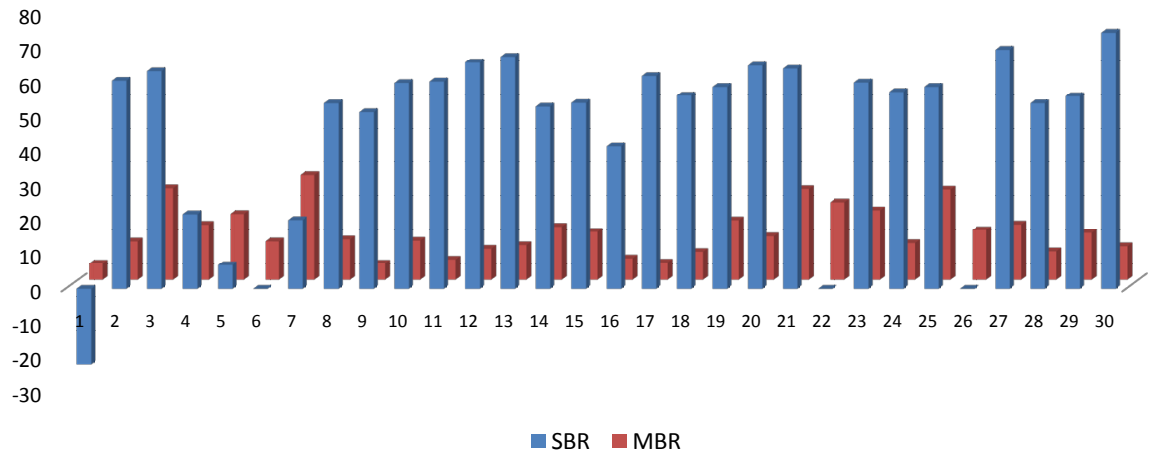

Figure 6. Comparison of COD removal after treatment with SBR and MBR. 
Table 7. Comparison of TDS, COD and ammonia removal after treatment with RO using SBR and MBR as pre-treatment.

\begin{tabular}{|c|c|c|c|c|c|c|}
\hline \multirow{2}{*}{ Day } & \multicolumn{2}{|c|}{ TDS } & \multicolumn{2}{|c|}{ COD } & \multicolumn{2}{|c|}{ Ammonia } \\
\hline & S-RO & M-RO & S-RO & M-RO & S-RO & M-RO \\
\hline 1 & 92.82 & 76.96 & 64.62 & 83.23 & 82.17 & 79.63 \\
\hline 2 & 90.26 & 85.88 & 74.87 & 83.64 & 80.23 & 77.81 \\
\hline 3 & 78.18 & 87.29 & 78.18 & 82.22 & 82.61 & 78.46 \\
\hline 4 & 95.29 & 85.19 & 81.33 & 84.91 & 82.55 & 80.71 \\
\hline 5 & 95.94 & 84.23 & 82.25 & 85.11 & 0 & 81.51 \\
\hline 6 & 94.39 & 80.95 & 0 & 88.17 & 87.5 & 81.88 \\
\hline 7 & 94.29 & 84.60 & 74.76 & 86.31 & 84.86 & 84.29 \\
\hline 8 & 92.33 & 80.84 & 74.33 & 86.91 & 84.26 & 84.48 \\
\hline 9 & 96.00 & 82.85 & 75.07 & 84.97 & 83.39 & 83.75 \\
\hline 10 & 94.69 & 84.03 & 76.49 & 86.91 & 84.62 & 80.27 \\
\hline 11 & 94.52 & 77.80 & 88.62 & 73.03 & 0 & 82.35 \\
\hline 12 & 93.98 & 85.00 & 84.88 & 79.29 & 80.99 & 84.29 \\
\hline 13 & 94.08 & 82.55 & 85.51 & 77.65 & 82.05 & 85.51 \\
\hline 14 & 92.94 & 79.57 & 82.75 & 76.90 & 81.57 & 83.93 \\
\hline 15 & - & 80.00 & 88.19 & 81.29 & 79.91 & 82.85 \\
\hline 16 & 87.9 & 81.70 & 85.7 & 76.09 & 78.84 & 80.28 \\
\hline 17 & 87.85 & 83.75 & 87.72 & 82.18 & 84.34 & 0.00 \\
\hline 18 & 87.14 & 83.93 & 86.22 & 85.28 & 80.9 & 0.00 \\
\hline 19 & 85.24 & 78.79 & 87.23 & 86.77 & 0 & 71.46 \\
\hline 20 & 87.27 & 78.95 & 84.52 & 88.55 & 80.2 & 81.25 \\
\hline 21 & 84.76 & 79.29 & 83.06 & 89.47 & 82.53 & 74.29 \\
\hline 22 & 86.41 & 86.92 & 83.4 & 90.12 & 78.25 & 76.25 \\
\hline 23 & 81.03 & 83.48 & 86.67 & 89.19 & 81.88 & 77.69 \\
\hline 24 & 88.00 & 86.50 & 83.21 & 90.26 & 80.09 & 79.00 \\
\hline 25 & 84.95 & 84.94 & 0 & 91.69 & 78.00 & 81.97 \\
\hline 26 & 0 & 86.67 & 85.11 & 92.33 & 79.19 & 80.15 \\
\hline Avg & 86.41 & 82.79 & 75.56 & 84.71 & 72.34 & 74.39 \\
\hline
\end{tabular}

S-RO - RO treatment with SBR as pre-treatment; M-RO - RO treatment with MBR as pre-treatment.

treatment with $95.94 \%$ removal. While MBR-RO combination resulted in $87.29 \%$ removal (Figure 7). Chemical oxygen demand was achieved maximum with the combination of MBR-RO $92.33 \%$ while competitive results were achieved with the combination SBR-RO also 88.62\% (Figure 8). Removal of ammonia was maximum with the combination SBR-RO (87.5\%), while competitive results were obtained with MBR-RO (85.51\%) (Figure 9).

From the results, it can be understood that individually SBR was effective over 


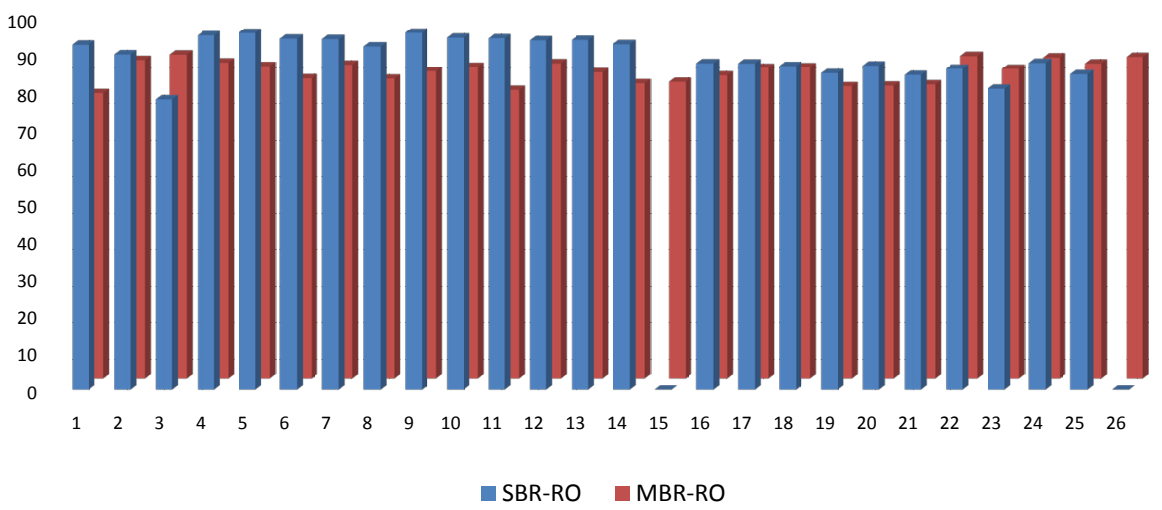

Figure 7. Comparison of TDS removal after treatment with RO using SBR and MBR as pre-treatment.

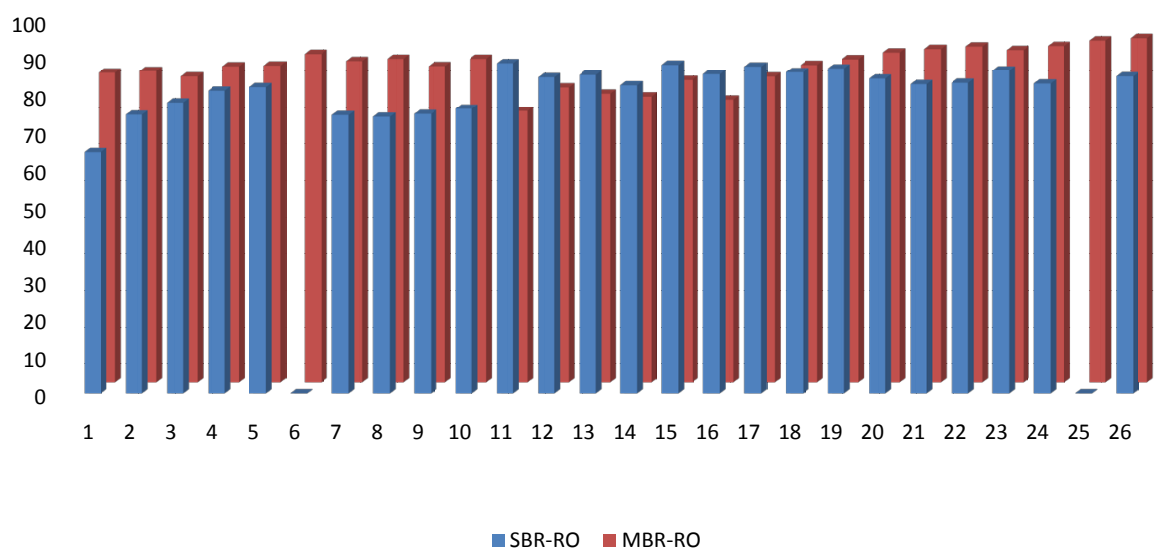

Figure 8. Comparison of COD removal after treatment with RO using SBR and MBR as pre-treatment.

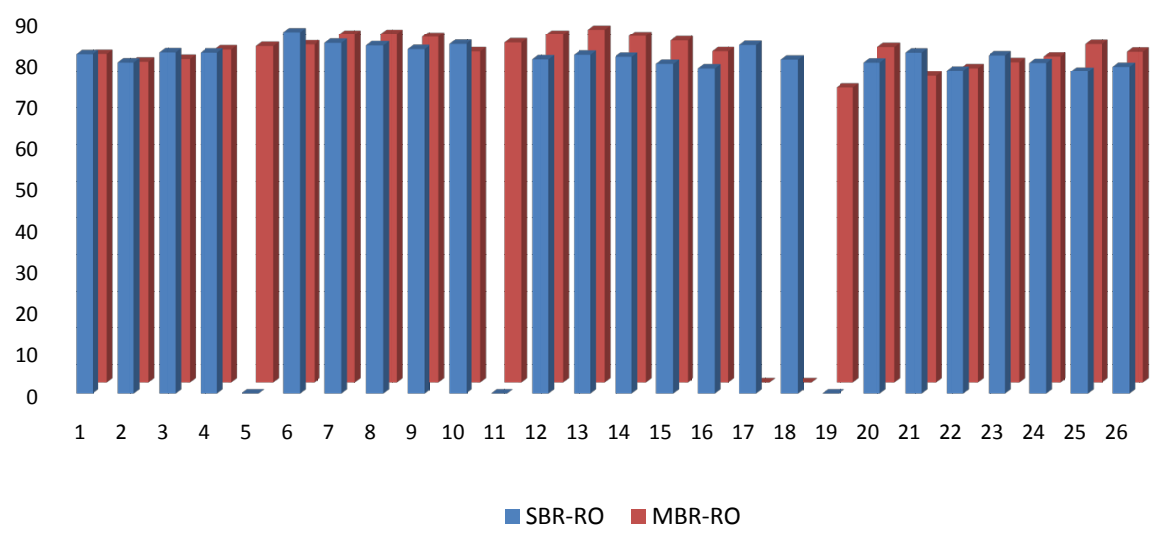

Figure 9. Comparison of ammonia removal after treatment with RO using SBR and MBR as pre-treatment.

MBR, while as pre-treatment the combination of MBR-RO was a little high since SBR-RO was equally competent. Since, reverse osmosis is efficient in removing solids, in biological treatment removal of chemical oxygen demand and ammonia are more desirable to get an overall effective treatment. Hence, the combina- 
tion of SBR-RO was tested on a full scale in further studies.

\section{Discussion}

The prime objective of the current research is to evaluate the efficiency of sequencing batch reactor (SBR) and membrane bioreactor (MBR) as pre-treatment for reverse osmosis (RO).

\subsection{Sequencing Batch Reactor}

Treatability of pharmaceutical wastewater using sequencing batch reactor (SBR) was tested on a pilot scale. During one of the months i.e., during June SBR outlet was fed to reverse osmosis (RO) to study the applicability of SBR as pre-treatment for RO. Efficiency of SBR is presented in terms of reduction in total dissolved solids and chemical oxygen demand. Details of SBR efficiency during the pilot trails is presented as follows:

\section{Removal of total dissolved solids}

Previous studies have shown that wastewaters containing high TDS when treated by SBR result in substantial reduction of chemical oxygen demand, since high TDS is considered to affect the dissolvability of oxygen in the wastewater [32]. The highest removal of TDS was noted as $27.32 \%$ during the month of September while the lowest with negative removal was observed during the month of March with $-29.28 \%$. Wu and Maskaly, 2018 [33] stated that at increasing TDS levels aerobic microorganisms and their metabolism are adversely affected leading to failure in the system. Upon effective working conditions removal of TDS is observed which is attributed to the oxidative degradation of dissolved solids [34]. Studies conducted by Mahvi et al., 2008 [35] on wastewater TDS removal reported a reduction of $61.25 \%$.

\section{Removal of Chemical Oxygen Demand}

In the present study, the highest and lowest COD removal was noted as $68.74 \%$ and 34.98\% during the months of March and May respectively. The reduction in COD is attributed to aeration and digestion processes, which are confirmed by previous studies showing 99\%, 90\%, 98\% and 94\% removal respectively [36] [37] [38]. As per the report of USEPA, SBR is effective in removal of COD and BOD along with nitrification, denitrification and suspended solids [39]. Amat et al., 2005 [40] obtained $99 \%$ to $86 \%$ of COD removal under varied loading factors on a lab scale SBR.

\section{$>$ Dissolved Oxygen Profile}

$2.0 \mathrm{mg} / \mathrm{l}$ of dissolved oxygen concentration is required for maximum nitrification rate. When concentration of dissolved oxygen falls below $0.5 \mathrm{mg} / \mathrm{l}$ and at a maximum of $1.0 \mathrm{mg} / \mathrm{l}$, it inhibits denitrification. The dissolved oxygen concentration of SBR system during the operation is understood to increase during the react stage as aeration is provided, the concentration decreases in the stages of settle, draw and idle due to ceasing of aeration and mixing processes. Moreover, concentration of dissolved oxygen is substantially related to activity of microor- 
ganisms in the system. Further, peak of dissolved oxygen occurs after complete depletion of ammonia which indicates the culmination of nitrification process [41]. An increase in dissolved oxygen is observed when all the organic matter is degraded, reducing the respiration of microbes.

\section{> Sequencing batch reactor as pre-treatment to Reverse Osmosis}

One-month trail runs were performed wherein treated effluent from SBR is fed to reverse osmosis. The results were promising with the higher end removal of TDS, COD and ammonia recorded as $96 \%, 88.62 \%$ and $87.50 \%$ respectively. Meagre studies are found in context of integrated treatment using SBR followed by RO especially for treating pharmaceutical wastewaters. Gangavarapu et al., 2015 [42] conducted a study on medium scale active pharmaceutical ingredient manufacturing industry that adopted recycling process through zero liquid discharge system. They reported the flow of effluent treatment process consisted of multi-effect evaporator followed by sequencing batch reactor which is concluded by reverse osmosis. They achieved reduction in total dissolved solids, total suspended solids and biological oxygen demand in the order of 99.2, 100 and 100 percent respectively. A combination of membrane sequencing batch reactor with reverse osmosis has achieved $90.9 \%$ reduction in chemical oxygen demand, $92 \%$ of total organic carbon and $91.5 \%$ of oil and grease from produced water of oil and gas field [43].

\subsection{Membrane Bioreactor}

MBR processes are experiencing exceptional growth in treating domestic and municipal wastewater during the past decade owing to many advantages like exceptional quality of effluent, lesser production of sludge, lower foot print and flexibility for expansion in future [44]. Industrial use of MBR technology gained attention attributed to the robustness in its process, resistance to high organic loading, ability to treat compounds that are difficult and inhibiting to treat [45]. Pharmaceutical wastewaters manufacturing vitamins were conventionally treated using two units of oxidation process wherein the treated water was unstable with greater amounts of suspended solids among other pollution parameters. Hence Feng et al., 2006 [46] suggested the use of MBR pilot plant to treat these waters instead of the conventional processes.

\section{$>$ Removal of Total Dissolved Solids}

TDS concentrations of permeate were in the range of $4856 \mathrm{mg} / \mathrm{l}$ to 32,000 $\mathrm{mg} / \mathrm{l}$. TDS removal was recorded to be $1.38 \%$ as the lowest and $29.25 \%$ as the highest. There exists a paucity in literature regarding removal of TDS by MBR. Almost all the studies focus on removal of TSS but not TDS. Moreover, TDS removal is always reported when MBR is used as a pre-treatment for RO. Hence, in the present study also the removal of TDS will be dealt in the following section of MBR as pre-treatment for RO.

\section{Removal of Total Suspended Solids}

In the present study, TSS concentrations in permeate were recorded to be zero 
0 with $100 \%$ removal. Removal of suspended solids effectively performed by membrane separation process, overcoming the limitations related to sludge settling properties [47]. MBR was employed for treatment of pharmaceutical wastewaters on a pilot scale in southern Taiwan. Performance was monitored for a duration of 140 days; it was observed that there was a regular logarithmic progress of viscosity in relation to TSS concentration [48]. 100\% removal of suspended solids with high quality effluent was reported by Shahbeig et al., 2013 [49] obtained $98 \%$ removal of TSS treated by MBR when ultra-filtration was used as a pre-treatment. Tee et al., 2016 [50] reported 92\% turbidity removal when mixed industrial wastewater was treatment in MBR.

\section{Removal of Chemical Oxygen Demand}

COD removal in the present study was attained from $4.77 \%$ to $30.35 \%$ which was contrary to the previous studies and the reason can be traced to the discussion provided by Di Trapani et al., 2014 [51]. Synthetic cephalosporin antibiotic wastewater water was treated using contact oxidation-hydrolysis-MBR the influent COD concentrations ranged between 2125 - 11,561 mg/L while the effluent concentrations obtained were 79 to $282 \mathrm{mg} / \mathrm{L}$. Further, the effluent BOD obtained was less than $10 \mathrm{mg} / \mathrm{L}$ [52]. A diminution in COD from $3000 \mathrm{mg} / \mathrm{L}$ to 45 $\mathrm{mg} / \mathrm{L}$ was obtained by integrated coagulation-contact oxidation-MBR for treating wastewater from pharmaceutical factory producing Lisinopril enalapril.

\section{Removal of Turbidity}

Virtuous removal of turbidity was recorded with permeate values recorded as $0.91 \mathrm{NTU}$ as the lowest and $40.1 \mathrm{NTU}$ as the highest. Turbidity removal is in the order of $80.90 \%$ being the lowest and $99.86 \%$ being the highest. Studies elsewhere reported the efficiency of MBR in terms of effective removal of suspended solids, leading to zero turbidity of wastewaters. Removal of specific organic pollutants along with higher removal of COD was achieved by Lipp et al., 2009 [53]. Exceptionally good quality of filtered effluent was obtained after treatment with MBR with turbidity of less than 1 NTU [54].

\section{Membrane bioreactor as pre-treatment for reverse osmosis}

When treated waters from MBR were fed to RO the removal efficiencies of various parameters were found to be significant with TDS removal to be $26.96 \%$ as the lowest and $87.29 \%$ as the highest. COD removal varied from $73.03 \%$ to $92.33 \%$. While hardness showed $93.33 \%$ - 100\% removal, ammonia removal was good with $71.46 \%$ being the lowest and $85.51 \%$ recorded as the highest. MBR treatment in combination with traditional methods for treating pharmaceutical effluents containing anti-inflammatory and antibiotic drugs has achieved $90.4 \%$ reduction in COD [23]. Latest literature review quoting previous studies acknowledged MBR technology as novel method of pretreatment prior to RO treatment for secondary effluent. Further, it has been reported that complete removal of all PhACs is not achieved by MBR or in fact any single treatment unit and hence advanced treatment techniques like NF, Ozone oxidation, advanced oxidation and $\mathrm{RO}$ are to be integrated to achieve 
complete removal of pollutants.

\subsection{Comparison of Sequencing Batch Reactor and Membrane Bioreactor}

In the present study maximum reduction of total dissolved solids was obtained by SBR with $31.82 \%$. On the other hand, MBR present lowest removals with $29.25 \%$. Chemical oxygen demand was the highest (69.54\%) with SBR, while MBR was stable with maximum of 30.35\% removal of COD. Lefebvre et al., 2014 [55] compared the efficiencies of SBR and MBR in treating pharmaceutical wastewaters produced from manufacturing of antibiotic penicillin. They reported better performance of both units at lower organic loading but faced with foaming issues upon increasing the organic load. Further, SBR was good in degrading aromatic compounds while MBR achieved good solids removal. Pilot-scale studies for treating municipal wastewaters using SBR and MBR were studied by Mirbagheri et al., 2017 [56]. They reported that SBR achieved 98.54\% of $\mathrm{BOD}_{5}$ removal while MBR achieved $97.1 \%$ of COD. They concluded that both the treatment options were suitable for treating municipal wastewater. MBR exhibited higher removal rates of pollutants over SBR with $99.5 \%$ vs. $82 \%$ for BOD $_{5} ; 70 \%$ vs. $47 \%$ for COD; $95 \%$ vs. $73 \%$ for TN and $96 \%$ vs. $71.4 \%$ for $\mathrm{NH}_{3}-\mathrm{N}$. The study opined requirement of post-treatment for effluents from both units owing to the high strength raw wastewater. Further, they stated that factors like technical expertise, footprint and membrane lifespan are to be considered when assessing the economic burden of adopting MBR treatment technology [57]. Apart from treatment efficiencies one important deciding factor for adopting a treatment technology is the associated cost. Some authors have focused on this aspect and presented their results. With reference to STPs the cost wise hierarchy is presented as MBR $<\mathrm{USAB}<\mathrm{SBR}<\mathrm{MBBR}$ with MBR requiring the highest and MBBR requiring the lowest cost. With this and removal efficiency it can be concluded that SBR would be most economical and efficient treatment technology that can be adopted in India. Further, MBR requires 25\% more economy in comparison to SBR. Moreover, with reference to treatment efficiency SBR is equally competent to MBR [58] [59].

\subsection{Comparison between $S B R$ and $M B R$ as Pre-Treatment for RO}

Total dissolved solids removal was the highest in the combination of SBR-RO treatment with $95.94 \%$ removal. While MBR-RO combination resulted in $87.29 \%$ removal. Chemical oxygen demand was achieved maximum with the combination of MBR-RO 92.33\% while competitive results were achieved with the combination SBR-RO also $88.62 \%$. Removal of ammonia was maximum with the combination SBR-RO (87.5\%), while competitive results were obtained with MBR-RO (85.51\%). High paucity in literature exists in comparing pre-treatment options for RO. Some of the workers elsewhere voted for SBR + RO/UF over MBR attributed to the cost-effectiveness associated with SBR. 
From the results and discussion, it can be understood that individually SBR was effective over MBR. Though as pre-treatment the combination of MBR-RO was a little high, SBR-RO was equally competent. Since, reverse osmosis is efficient in removing solids, removal of chemical oxygen demand and ammonia in biological treatment is more desirable to get an overall effective treatment. Hence, the combination of SBR-RO was tested on a full scale in the further studies.

\section{Conclusions}

Removal of chemical oxygen demand from wastewaters requires adopting biological treatment. Available conventional biological treatments are not able to treat to the required standards. Literature review stated the use of hybrid processes or combination of various treatment technologies to achieve discharge standards. Hence, in the present study a combination of advanced biological process and advanced physical membrane separation process were chosen to test their combined efficiency in treating pharmaceutical wastewaters. The biological treatment methods evaluated for their efficiency are sequencing batch reactor and membrane bioreactor, further their suitability as pre-treatment to reverse osmosis treatment was also evaluated.

Efficiency comparison among biological treatments SBR and MBR: Total dissolved solids removal by SBR was $31.82 \%$ and MBR showed $29.25 \%$. SBR even though presented the highest removal was quite fluctuating in treatment process. Chemical oxygen demand removal by SBR was $69.54 \%$ and MBR showed $30.35 \%$ removal of COD. Since the prime objective of biological treatment is removal of chemical oxygen demand and SBR was efficient over MBR, SBR was selected for biological treatment of pharmaceutical wastewaters.

Efficiency comparison among combined treatments of SBR-RO and MBR-RO: Removal of total dissolved solids was the highest in the combination of SBR-RO treatment with $95.94 \%$ removal. While MBR-RO combination resulted in $87.29 \%$ removal. Chemical oxygen demand was achieved maximum with the combination of MBR-RO 92.33\% while competitive results were achieved with the combination SBR-RO also with $88.62 \%$ removal. Removal of ammonia was maximum with the combination SBR-RO 87.5\%, while competitive results were obtained with MBR-RO $85.51 \%$. From the results, it can be understood that SBR was efficient in removing ammonia and total dissolved solids and was equally competent in removing chemical oxygen demand. Since, reverse osmosis is efficient in removing solids, in biological treatment removal of chemical oxygen demand and ammonia are more desirable to get an overall effective treatment. Hence, the combination of SBR-RO was tested on a full scale in the further studies.

\section{Conflicts of Interest}

The authors declare no conflicts of interest regarding the publication of this paper. 


\section{References}

[1] Takdastan, A. and Pazoki, M. (2011) Study of Biological Excess Sludge Reduction in Sequencing Batch Reactor by Heating the Reactor. Asian Journal of Chemistry, 23, 29.

[2] Mace, S. and Mata-Alvarez, J. (2002) Utilization of SBR Technology for Wastewater Treatment: An Overview. Industrial \& Engineering Chemistry Research, 41, 5539-5553. https://doi.org/10.1021/ie0201821

[3] Giordano, A., Stante, L., Pirozzi, F., Cesaro, R. and Bortone, G. (2005) Sequencing Batch Reactor Performance Treating PAH Contaminated Lagoon Sediments. Journal of Hazardous Materials, 119, 159-166. https://doi.org/10.1016/j.jhazmat.2004.12.002

[4] Lamine, M., Bousselmi, L. and Ghrabi, A. (2007) Biological Treatment of Grey Water Using Sequencing Batch Reactor. Desalination, 215, 127-132. https://doi.org/10.1016/j.desal.2006.11.017

[5] Jin, X., Li, E., Lu, S., Qiu, Z. and Sui, Q. (2013) Coking Wastewater Treatment for Industrial Reuse Purpose: Combining Biological Processes with Ultrafiltration, Nanofiltration and Reverse Osmosis. Journal of Environmental Sciences, 25, 1565-1574. https://doi.org/10.1016/S1001-0742(12)60212-5

[6] Obaja, D., Mace, S., Costa, J., Sans, C. and Mata-Alvarez, J. (2003) Nitrification, Denitrification and Biological Phosphorus Removal in Piggery Wastewater Using a Sequencing Batch Reactor. Bioresource Technology, 87, 103-111. https://doi.org/10.1016/S0960-8524(02)00229-8

[7] Ketchum Jr., L.H. (1997) Design and Physical Features of Sequencing Batch Reactors. Water Science and Technology, 35, 11-18. https://doi.org/10.1016/S0273-1223(96)00873-6

[8] Gali, A., Dosta, J., Lopez-Palau, S. and Mata-Alvarez, J. (2008) SBR Technology for High Ammonium Loading Rates. Water Science and Technology, 58, 467-472.

https://doi.org/10.2166/wst.2008.408

[9] Rodríguez, D.C., Ramírez, O. and Mesa, G.P. (2011) Behavior of Nitrifying and Denitrifying Bacteria in a Sequencing Batch Reactor for the Removal of Ammoniacal Nitrogen and Organic Matter. Desalination, 273, 447-452. https://doi.org/10.1016/j.desal.2011.01.068

[10] Oliveira, R.P., Ghilardi, J.A., Ratusznei, S.M., Rodrigues, J.A.D., Zaiat, M. and Foresti, E. (2008) Anaerobic Sequencing Batch Biofilm Reactor Applied to Automobile Industry Wastewater Treatment: Volumetric Loading Rate and Feed Strategy Effects. Chemical Engineering and Processing: Process Intensification, 47, 1374-1383. https://doi.org/10.1016/j.cep.2007.06.014

[11] Sarioglu, M. (2005) Biological Phosphorus Removal in a Sequencing Batch Reactor by Using Pure Cultures. Process Biochemistry, 40, 1599-1603. https://doi.org/10.1016/j.procbio.2004.06.020

[12] Maheswara, U., Ganguru, R. and Kulkarni, S. (2015) Studies on Zero Liquid Discharge (ZLD) Plant in API Manufacturing Unit. Environment, 6, 7.

[13] Carucci, A., Lindrea, K., Majone, M. and Ramadori, R. (1995) Dynamics of the Anaerobic Utilization of Organic Substrates in an Anaerobic/Aerobic Sequencing Batch Reactor. Water Science and Technology, 31, 35-43.

https://doi.org/10.2166/wst.1995.0068

[14] Chiavola, A., Farabegoli, G. and Antonetti, F. (2014) Biological Treatment of Olive Mill Wastewater in a Sequencing Batch Reactor. Biochemical Engineering Journal, 85, 71-78. https://doi.org/10.1016/j.bej.2014.02.004 
[15] Hai, R., He, Y., Wang, X. and Li, Y. (2015) Simultaneous Removal of Nitrogen and Phosphorus from Swine Wastewater in a Sequencing Batch Biofilm Reactor. Chinese Journal of Chemical Engineering, 23, 303-308. https://doi.org/10.1016/j.cjche.2014.09.036

[16] Elmolla, E.S. and Chaudhuri, M. (2011) The Feasibility of Using Combined $\mathrm{TiO}_{2}$ Photocatalysis-SBR Process for Antibiotic Wastewater Treatment. Desalination, 272, 218-224. https://doi.org/10.1016/j.desal.2011.01.020

[17] Judd, S. (2010) The MBR Book: Principles and Applications of Membrane Bioreactors for Water and Wastewater Treatment. Elsevier, Amsterdam.

[18] Wang, L.K. and Menon, R. (2011) Treatment of Industrial Effluents, Municipal Wastes, and Potable Water by Membrane Bioreactors. In: Membrane and Desalination Technologies, Humana Press, Totowa, NJ, 201-236. https://doi.org/10.1007/978-1-59745-278-6_5

[19] Liaozhi, M. (2010) MBR Process of Fermentation Class Pharmaceutical Wastewater Treatment Pilot Study. Journal of China Water \& Wastewater, 26, 131-133.

[20] Hafez, A.I., El-Manharawy, M.S. and Khedr, M.A. (2002) RO Membrane Removal of Unreacted Chromium from Spent Tanning Effluent. A Pilot-Scale Study, Part 2. Desalination, 144, 237-242. https://doi.org/10.1016/S0011-9164(02)00318-1

[21] Hafez, A. and El-Mariharawy, S. (2004) Design and Performance of the Two-Stage/ Two-Pass RO Membrane System for Chromium Removal from Tannery Wastewater. Part 3. Desalination, 165, 141-151. https://doi.org/10.1016/j.desal.2004.06.016

[22] Marrot, B., Barrios-Martinez, A., Moulin, P. and Roche, N. (2004) Industrial Wastewater Treatment in a Membrane Bioreactor: A Review. Environmental Progress, 23, 59-68. https://doi.org/10.1002/ep.10001

[23] Radjenovic, J., Petrovic, M. and Barceló, D. (2007) Analysis of Pharmaceuticals in Wastewater and Removal Using a Membrane Bioreactor. Analytical and Bioanalytical Chemistry, 387, 1365-1377. https://doi.org/10.1007/s00216-006-0883-6

[24] Sahar, E., David, I., Gelman, Y., Chikurel, H., Aharoni, A., Messalem, R. and Brenner, A. (2011) The Use of RO to Remove Emerging Micropollutants Following CAS/UF or MBR Treatment of Municipal Wastewater. Desalination, 273, 142-147. https://doi.org/10.1016/j.desal.2010.11.004

[25] Le-Minh, N., Coleman, H.M., Khan, S.J., Van Luer, Y., Trang, T.T.T., Watkins, G. and Stuetz, R.M. (2010) The Application of Membrane Bioreactors as Decentralised Systems for Removal of Endocrine Disrupting Chemicals and Pharmaceuticals. Water Science and Technology, 61, 1081-1088. https://doi.org/10.2166/wst.2010.884

[26] Ho, W. and Sirkar, K. (2012) Membrane Handbook. Springer Science \& Business Media, New York.

[27] Brauns, E., Van Hoof, E., Molenberghs, B., Dotremont, C., Doyen, W. and Leysen, R. (2002) A New Method of Measuring and Presenting the Membrane Fouling Potential. Desalination, 150, 31-43. https://doi.org/10.1016/S0011-9164(02)00927-X

[28] Abid, M.F., Zablouk, M.A. and Abid-Alameer, A.M. (2012) Experimental Study of Dye Removal from Industrial Wastewater by Membrane Technologies of Reverse Osmosis and Nanofiltration. Iranian Journal of Environmental Health Science \& Engineering, 9, 17. https://doi.org/10.1186/1735-2746-9-17

[29] del Pino, M.P. and Durham, B. (1999) Wastewater Reuse through Dual-Membrane Processes: Opportunities for Sustainable Water Resources. Desalination, 124, 271-277. https://doi.org/10.1016/S0011-9164(99)00112-5 
[30] Qin, J.J., Oo, M.H., Lee, H. and Kolkman, R. (2004) Dead-End Ultrafiltration for Pretreatment of RO in Reclamation of Municipal Wastewater Effluent. Journal of Membrane Science, 243, 107-113. https://doi.org/10.1016/j.memsci.2004.06.010

[31] Xu, J., Kent, F.C. and Farahbakhsh, K. (2011) An Evaluation of MBR and Conventional Pretreatment for Reverse Osmosis for Water Reclamation. Journal of Water Reuse and Desalination, 1, 88-98. https://doi.org/10.2166/wrd.2011.041

[32] Pendashteh, A.R., Abdullah, L.C., Fakhru'l-Razi, A., Madaeni, S.S., Abidin, Z.Z. and Biak, D.R.A. (2012) Evaluation of Membrane Bioreactor for Hypersaline Oily Wastewater Treatment. Process Safety and Environmental Protection, 90, 45-55. https://doi.org/10.1016/j.psep.2011.07.006

[33] Wu, S. and Maskaly, J. (2018) Study on the Effect of Total Dissolved Solids (TDS) on the Performance of an SBR for COD and Nutrients Removal. Journal of Environmental Science and Health, Part A, 53, 146-153. https://doi.org/10.1080/10934529.2017.1383130

[34] Singh, S. and Varshney, M. (2013) Evaluation of Functioning of Waste Water Treatment Plant at Chandrawati Education Society, Jaipur: A Case Study. Evaluation, 2, 127-139.

[35] Mahvi, A.H. (2008) Application of Agricultural Fibers in Pollution Removal from Aqueous Solution. International Journal of Environmental Science \& Technology, 5, 275-285. https://doi.org/10.1007/BF03326022

[36] Ding, D., Feng, C., Jin, Y., Hao, C., Zhao, Y. and Suemura, T. (2011) Domestic Sewage Treatment in a Sequencing Batch Biofilm Reactor (SBBR) with an Intelligent Controlling System. Desalination, 276, 260-265. https://doi.org/10.1016/j.desal.2011.03.059

[37] Tian, W.D., Li, W.G., Zhang, H., Kang, X.R. and van Loosdrecht, M.C. (2011) Limited Filamentous Bulking in Order to Enhance Integrated Nutrient Removal and Effluent Quality. Water Research, 45, 4877-4884. https://doi.org/10.1016/j.watres.2011.06.034

[38] Ghehi, T.J., Mortezaeifar, S., Gholami, M., Kalantary, R.R. and Mahvi, A.H. (2014) Performance Evaluation of Enhanced SBR in Simultaneous Removal of Nitrogen and Phosphorous. Journal of Environmental Health Science and Engineering, 12, 134. https://doi.org/10.1186/s40201-014-0134-2

[39] USEPA (2000) Wastewater, Technology Fact Sheet: Package Plants. U.S. Environmental Protection Agency, Office of Water, Washington EPA 832-F-00-016.

[40] Amat, A.M., Arques, A., Miranda, M.A. and López, F. (2005) Use of Ozone and/or UV in the Treatment of Effluents from Board Paper Industry. Chemosphere, 60, 1111-1117. https://doi.org/10.1016/j.chemosphere.2004.12.062

[41] Holman, J.B. and Wareham, D.G. (2005) COD, Ammonia and Dissolved Oxygen Time Profiles in the Simultaneous Nitrification/Denitrification Process. Biochemical Engineering Journal, 22, 125-133. https://doi.org/10.1016/j.bej.2004.09.001

[42] Gangavarapu, S., Ganguru, U.M.R., Kulkarni, S., MurthyBrahmandam, N. and Anumula, S. (2015) Membrane Bioreactor Coupled with Sequential Batch Reactor: A Supportive Technology in Effluent Recycling of API Manufacturing Industries. International Journal of New Technology and Research, 1, 46-49.

[43] Fakhru'l-Razi, A., Pendashteh, A., Abidin, Z.Z., Abdullah, L.C., Biak, D.R.A. and Madaeni, S.S. (2010) Application of Membrane-Coupled Sequencing Batch Reactor for Oilfield Produced Water Recycle and Beneficial Re-Use. Bioresource Technolo$g y$, 101, 6942-6949. https://doi.org/10.1016/j.biortech.2010.04.005 
[44] Ming, Y. and De-Sheng, W. (2010) Experimental Study of Antibiotic Wastewater. Journal of MBR Treatment. Environmental Protection and Recycling Economy, 9, 54-55.

[45] Klinkow, N., Oleksy-Frenzel, J. and Jekel, M. (1998) Toxicity-Directed Fractionation of Organic Compounds in Tannery Wastewater with Regard to Their Molecular Weight and Polarity. Water Research, 32, 2583-2592. https://doi.org/10.1016/S0043-1354(98)00017-7

[46] Jia, H. (2018) Nitrogen Removal by Algae-Bacteria Consortia: Batch Tests and Photo Sequence Batch Reactor.

[47] Urase, T., Kagawa, C. and Kikuta, T. (2005) Factors Affecting Removal of Pharmaceutical Substances and Estrogens in Membrane Separation Bioreactors. Desalination, 178, 107-113. https://doi.org/10.1016/j.desal.2004.11.031

[48] Chang, C.Y., Chang, J.S., Vigneswaran, S. and Kandasamy, J. (2008) Pharmaceutical Wastewater Treatment by Membrane Bioreactor Process-A Case Study in Southern Taiwan. Desalination, 234, 393-401. https://doi.org/10.1016/j.desal.2007.09.109

[49] Shahbeig, H., Mehrnia, M.R., Mohammadi, A.R., Moghaddam, P.E. and Rouini, M.R. (2017) Pharmaceutical Wastewater Treatment Using Membrane BioreactorOzonation System. Water and Environment Journal, 31, 57-63.

https://doi.org/10.1111/wej.12222

[50] Tee, P.F., Abdullah, M.O., Tan, I.A.W., Rashid, N.K.A., Amin, M.A.M., Nolasco-Hipolito, C. and Bujang, K. (2016) Review on Hybrid Energy Systems for Wastewater Treatment and Bio-Energy Production. Renewable and Sustainable Energy Reviews, 54, 235-246. https://doi.org/10.1016/j.rser.2015.10.011

[51] Di Trapani, D., Di Bella, G., Mannina, G., Torregrossa, M. and Viviani, G. (2015) Effect of $\mathrm{C} / \mathrm{N}$ Shock Variation on the Performances of a moving Bed Membrane Bioreactor. Bioresource Technology, 189, 250-257. https://doi.org/10.1016/j.biortech.2015.03.143

[52] Fazal, S., Zhang, B., Zhong, Z., Gao, L. and Lu, X. (2015) Membrane Separation Technology on Pharmaceutical Wastewater by Using MBR (Membrane Bioreactor). Journal of Environmental Protection, 6, 299. https://doi.org/10.4236/jep.2015.64030

[53] Lipp, P., Groß, H.J. and Tiehm, A. (2012) Improved Elimination of Organic Micropollutants by a Process Combination of Membrane Bioreactor (MBR) and Powdered Activated Carbon (PAC). Desalination and Water Treatment, 42, 65-72. https://doi.org/10.1080/19443994.2012.683137

[54] Kootenaei, F.G. and Aminirad, H. (2014) Membrane Biological Reactors (MBR) and Their Applications for Water Reuse. International Journal of Advanced Biological and Biomedical Research, 2, 1951-1962.

[55] Lefebvre, O., Shi, X., Wu, C.H. and Ng, H.Y. (2013) Biological Treatment of Pharmaceutical Wastewater from the Antibiotics Industry. Water Science and Technology, 69, 855-861. https://doi.org/10.2166/wst.2013.729

[56] Mirbagheri, S.A., SM, S.Y., Rafeidehkordi, N. and Vakilian, R. (2017) Comparison of CAS, MBR, SBR, and Biolak Treatment Systems in Removal of BOD and COD from Municipal Wastewater-Case Study: Ekbatan Wastewater Treatment Plant. 15th International Conference on Environmental Science and Technology, Rhodes, Greece, 31 August-2 September 2017, 1-5.

[57] El-Fadel, M. and Hashisho, J. (2014) A Comparative Examination of MBR and SBR Performance for the Treatment of High-Strength Landfill Leachate. Journal of the Air \& Waste Management Association, 64, 1073-1084.

https://doi.org/10.1080/10962247.2014.907840 
[58] Matamoros, V., Rodríguez, Y. and Albaigés, J. (2016) A Comparative Assessment of Intensive and Extensive Wastewater Treatment Technologies for Removing Emerging Contaminants in Small Communities. Water Research, 88, 777-785. https://doi.org/10.1016/j.watres.2015.10.058

[59] Reddy, S.R., Saritha, V., Karnena, M.K. and Dwarapureddi, B.K. (2017) Combined SBR and RO Pilot Scale Treatment for Pharmaceutical Wastewater. Desalination and Water Treatment, 98, 45-51. https://doi.org/10.5004/dwt.2017.21579 